\title{
Transposition
}

Musique et Sciences Sociales

\section{Randal J. Stevens, The Devil's Music: How Christians Inspired, Condemned, and Embraced Rock'n'Roll}

Cambridge, Harvard University Press, 2018

\section{Gérôme Guibert}

\section{OpenEdition}

\section{Journals}

Édition électronique

URL : http://journals.openedition.org/transposition/5751

DOI : 10.4000/transposition. 5751

ISSN : 2110-6134

\section{Éditeur}

CRAL - Centre de recherche sur les arts et le langage

\section{Référence électronique}

Gérôme Guibert, «Randal J. Stevens, The Devil's Music: How Christians Inspired, Condemned, and Embraced Rock'n'Roll », Transposition [En ligne], 9 | 2021, mis en ligne le 15 décembre 2020, consulté le 23 avril 2021. URL : http://journals.openedition.org/transposition/5751 ; DOI : https://doi.org/ 10.4000/transposition.5751

Ce document a été généré automatiquement le 23 avril 2021

\section{(c) (i) (-)}

La revue Transposition est mise à disposition selon les termes de la Licence Creative Commons Attribution - Partage dans les Mêmes Conditions 4.0 International. 


\title{
Randal J. Stevens, The Devil's Music: How Christians Inspired, Condemned, and Embraced Rock'n'Roll
}

Cambridge, Harvard University Press, 2018

\author{
Gérôme Guibert
}

\section{RÉFÉRENCE}

Randal J. Stevens, The Devil's Music: How Christians Inspired, Condemned, and Embraced Rock'n'Roll, Cambridge, Harvard University Press, 2018, 344 p.

1 «Anti Christ, Death to Christ » (AC/DC), « Knights in Satanic Service » (KISS), il fut une période, le début des années 1980 , où les soupçons blasphématoires à l'égard du rock'n'roll émanant des franges conservatrices $\mathrm{du}$ protestantisme étaient particulièrement élevés aux États-Unis. Certains révérends, évangélistes ou fondamentalistes organisaient même des rencontres publiques avec des discours se terminant par de grands feux qui permettaient de brûler des disques et autres effigies de rock et pop stars. La musique était considérée comme pécheresse, dérangée et démoniaque. Lors de la candidature pour sa réélection, à la fin de l'année 1984, Ronald Reagan ralliait son soutien à ce mouvement de protestation, se plaignant du rôle ambigu de l'industrie du disque envers l'influence néfaste possible du satanisme sur la jeunesse. Évidemment l'époque est aussi celle où, opposés à la puissance des téléévangélistes et des protestations rigoristes, des albums de divers « genre » musicaux, y compris de punk rock ou même de rock progressif attaquaient frontalement en réaction, la religion. C'est aussi celle où des citoyens minoritaires tiraient la sonnette d'alarme, rapprochant ces manifestations publiques de destructions de biens culturels par le feu au contexte du régime nazi de la fin des années 1930.

2 Ces combats symboliques et médiatiques, souvent intenses, sont ceux qui sont décrits dans The Devil's Music: How Christians Inspired, Condemned, and Embraced Rock'n'Roll, un 
ouvrage de plus de 300 pages écrit par Randal J. Stevens, Professeur en études américaines et britanniques à l'Université d'Oslo. L'ouvrage est d'autant plus instructif qu'on n'a jamais connu en France, au nouveau national, un tel front d'opposition de la chrétienté, ou au moins de certaines communautés chrétiennes, à l'encontre du rock ou plus largement de la musique pop ${ }^{1}$. On n'a jamais non plus, d'un autre côté, depuis le début du XXI ${ }^{e}$ siècle, été baigné dans le rock chrétien et ses rassemblements comme cela est décrit dans l'ouvrage (même s'ils ont pu parfois s'exprimer à la marge). Dans notre pays, on a longtemps accueilli avec scepticisme ce genre d'information concernant la réception des musiques populaires émanant des États-Unis. L'intérêt de ce livre est justement de remettre en perspective ces affrontements dans la spécificité du contexte américain - notamment la place des divers courants des églises réformées dans leurs acceptions conservatrices et progressistes.

3 L'ouvrage est construit sur le mode du récit reprenant chronologiquement les faits en les étayant par les prises de parole médiatiques des acteurs concernés. Les archives sont issues à la fois de médias écrits, journaux et magazines, et de médias audiovisuels (télévision et radio). A travers elles, l'ensemble des parties prenantes est convoqué, révérends, collectifs de croyants, musiciens, hommes politiques, simples témoins d'évènements ou de décisions pour ou contre le rock. A cela s'ajoute plus d'une vingtaine d'illustrations situées dans leur contexte et particulièrement éclairantes. Il peut s'agir de photos d'écran d'émissions télévisées² ${ }^{2}$ de documents et guides religieux imprimés à propos $\mathrm{du}$ rock $^{3}$, de photos de prédicateurs en plein discours, de photos d'affiches ou de concerts, de caricatures de journaux. Outre quatre-vingts pages de notes et un index utile de dix pages qui répertorie notamment les artistes, les genres musicaux et les noms de prédicateurs, l'ouvrage est construit en cinq chapitres qui suivent un déroulé chronologique. Le premier traite du rock'n'roll dans les années 1950, retraçant l'émergence de la panique morale en particulier face à Elvis Presley. Le second chapitre « Race, Religion, and Rock'n'Roll », montre comment à la fin des années 1950, le rock est associé à une musique de sauvage, aux rythmes voodoo. L'achat de disques «negro » est considéré comme menaçant pour la morale religieuse, bien davantage encore que le jazz des années 1930. De même que les films comme Wild One (1953), Rebel Without a Cause (1955), Black Board Jungle (1955) ou The Delinquents (1957) sont accusés d'influencer négativement la jeunesse. Si la polémique sur la dimension perverse et satanique du rock semble se calmer au début des années 1960, elle sera relancée avec les tournées des fab four et la dévotion de leurs fans. C'est ce qu'expose le troisième chapitre, "Beatles. Christianity, and the Conservative Backlash ", qui expose implacablement la dimension subversive des Beatles aux ÉtatsUnis. L'hapax est le moment qui suit la déclaration de John Lennon du 4 mars 1966 selon laquelle «Les Beatles sont plus populaires que Jesus Christ, dorénavant». L'ouvrage montre méticuleusement comment ces propos ont pu enflammer les ÉtatsUnis, en exposant les incroyables mouvements de foule des concerts de 1964 et la tournée à haut risque de la seconde partie de l'année 1966, qui aboutira finalement à la décision radicale d'arrêt définitif des concerts pour les Beatles. Étant donné la manière dont on juge aujourd'hui le groupe, on est particulièrement surpris de la virulence des positions auxquelles les musiciens amenaient alors leurs opposants et leurs défenseurs aux États-Unis. Le quatrième et avant-dernier chapitre "The Advent of Jesus Rock » évoque également des faits peu connus et souvent caricaturés. L'émergence d'un courant musical de croyants « progressistes » influencés par le mouvement hippie et la contre-culture post-68. Il arrive dans une période où les autorités religieuses cherchent 
un langage permettant de retenir les nouvelles générations au sein d'une sociabilité religieuse. Ce tournant est rendu possible par le changement de position du charismatique révérend prédicateur Bill Graham qui va, d'opposant au rock'n'roll, peu à peu devenir entre 1967 et 1970, un défenseur du Christian rock. Il supportera notamment le festival Explo' 72 qui fait la promotion de musiciens chrétiens œuvrant dans les domaines du folk rock et de la country music. A l'époque, les Beatles sont morts et Georges Harrison a même atteint le succès avec un titre intitulé «My Sweet Lord ». Le dernier chapitre enfin, évoque la réaction fondamentaliste au rock chrétien par les religieux conservateurs. Des succès tels que la comédie musicale Jesus Christ Superstar dont la bande originale est vendue sous forme d'album et qui sera exploitée au cinéma dans une version filmée en 1973 posent problème. Pour les chrétiens conservateurs, il faut éloigner la jeunesse de l'immoralité, de la musique rock, et plus largement de la culture hollywoodienne. La réaction fondamentaliste croît au cours des années 1970 et trouvera son apogée au milieu des années 1980. Ainsi, les groupes de rock chrétiens, et notamment ceux associés au heavy metal (on parle de white metal) ${ }^{4}$ comme Stryper ne sont pas considérés comme d'authentiques croyants et font polémique. Ils donneraient une mauvaise image de la religion. Pourtant la réaction conservatrice anti-rock ne perdurera pas dans les années 1990. Même si les anciens Jesus People sont devenus tendanciellement des chrétiens qui votent pour le parti républicain, leurs enfants n'associeront plus les musiques populaires à un phénomène problématique. L'épilogue de l'ouvrage le montre en prenant notamment l'exemple du groupe irlandais U2 et de son chanteur Bono, qui revendiquent leur foi chrétienne. L'auteur donne également l'exemple de groupes de gangsta rap chrétien ou de déclinaisons évangéliques gothiques, indie pop, death metal, grindcore ou electronic dance music acceptées par des évangéliques américains, y compris conservateurs. Au final, un ouvrage particulièrement instructif. Du point de vue du contenu, la seule interrogation que je pourrais avoir concerne l'absence de certains éléments pourtant significatifs dans la médiatisation des tensions entre rock et religion, tel le personnage de Charles Manson et les actes terroristes commis par sa secte à la fin des années $1960^{5}$, ou encore le rôle du PMRC (Parents Music Resource Center) et sa lutte contre le satanisme au milieu des années $1980^{6}$.

\section{NOTES}

1. Si ce n'est quelques exemples circonscrits dans le temps et l'espace, comme le festival Hellfest entre 2007 et 2012. Cf. GUIBERT Gérôme, «Le Hellfest, arène discursive. Sociologie des festivals de musique live comme sphères publiques ", Criminocorpus, sept. 2019, disponible sur : http://journals.openedition.org/criminocorpus/639 consulté le 2 mai 2020

2. Disponibles en DVD ou sur Internet (les adresses Youtube ou Viméo sont spécifiées)

3. Issues de la Southern Baptist Historical Library and Archives, Nashville, Tennessee et du Flower Pentecostal Heritage Center, Springfield, Missouri. 
4. GUIBERT Gérôme, «À propos de deux ouvrages récents sur le black metal », Volume!, vol. 1, $\mathrm{n}^{\circ}$ 1, 2002, p. 124-127, disponible sur : https://journals.openedition.org/volume/ 4761 consulté le 2 mai 2020.

5. CARLIN Gerald et JONES Mark, "Helter Skelter" et l'héritage polémique des années $1960 »$ (traduction de Jedediah Sklower), Volume!, vol. 10, n 2, 2012, p. 33-49, disponible sur : https://journals.openedition.org/volume/3403 consulté le 2 mai 2020.

6. BENETOllo Anne, Rock et Politique. Censure, Opposition, Intégration, Paris, L'Harmattan, 1999.

\section{AUTEURS}

\section{GÉRÔME GUIBERT}

Gérôme Guibert est maître de conférences en sociologie à l'Université Sorbonne Nouvelle Paris 3, et directeur adjoint de l'Institut de la communication et des Médias (UFR Arts \& Médias). Il est chercheur à l'Irméccen (Institut de Recherche Médias, culture, communication et numérique), EA $\mathrm{n}^{\circ} 7546$ et cofondateur de la revue Volume! dont il a été directeur de la publication entre 2009 et 2017. Ses trois axes de recherche principaux concernent les industries culturelles, les scènes musicales locales et les dimensions culturelles des genres musicaux. Il a notamment publié (avec C. Rudent), Made In France. Studies in Popular Music, Routledge, 2018 ; (avec F. Rebillard et F. Rochelandet), Médias, culture et numérique, Armand Colin, 2016 ; (avec D. Sagot-Duvauroux), Musiques actuelles, ça part en live. Analyse économique d'une filière culturelle, DEPS/IRMA, 2013 ; La production de la culture. Le cas des musiques amplifiées en France, Seteun/IRMA, 2006. 